\title{
From drug-induced headache to medication overuse headache. A short epidemiological review, with a focus on Latin American countries
}

\author{
Marta Allena · Zaza Katsarava · Giuseppe Nappi · \\ the COMOESTAS Consortium
}

Received: 12 October 2008/ Accepted: 20 January 2009/Published online: 24 February 2009

(C) Springer-Verlag 2009

\begin{abstract}
Medication overuse headache (MOH) is a daily or almost-daily type of headache that results from the chronicization, usually migraine or tension-type headache, as a consequence of the progressive increase of intake of symptomatic drugs. MOH is now the third most frequent type of headache and affects a percentage of $1-1.4 \%$ of the general population. The currently available data on the impact of chronic headache associated with analgesic overuse in specialist headache centres confirm, beyond doubt, the existence of a serious health problem. Limited amount of data exists on the burden and impact of $\mathrm{MOH}$ in
\end{abstract}

COMOESTAS Consortium: C. Tassorelli (Project Manager), G. Sances, G. Sandrini, F. Blandini, P. Rossi (IRCCS "Neurological Institute C. Mondino" Foundation, University Centre for Headache and Adaptive Disorders, Pavia), R. Jensen (Region Hovedstaden, Glostrup Amtssygehuset), M. Lainez (Fundación de la Comunidad Valenciana para la Investigación Biomédica, la Docencia y la Cooperación Internacional y para el Desarrollo del Hospital Clínico Universitario de Valencia-Spain), D. Mueller

(Universitaetsklinikum Essen), J. Leston, M.T. Goicoichea

(Fundacion para la Lucha contra las Enfermedades Neurologicas de la Infanzia, Buenos Aires-Argentina), R. Fadic (Pontificia Universidad Catolica de Chile, Santiago-Chile).

COMOESTAS Project-EC contract number 215366

(COMOESTAS) FP7-Thematic priority ICT,

www.comoestas-project.eu

M. Allena $(\bowtie) \cdot$ G. Nappi

IRCCS "Neurological Institute C. Mondino" Foundation,

University Centre for Headache and Adaptive Disorders

(UCADH), Pavia Section, Via Mondino 2, 27100 Pavia, Italy

e-mail: marta.allena@mondino.it

Z. Katsarava

Department of Neurology, University Hospital of Essen,

Essen, Germany

G. Nappi

Chair of Neurology, University "La Sapienza”, Rome, Italy
Latin American Countries. In this review, we summarise the reliable information from the literature on the epidemiological impact of $\mathrm{MOH}$.

Keywords Drug-induced headache .

Medication overuse headache - Epidemiological impact .

Prevalence $\cdot$ Latin American countries

\section{Introduction}

Inappropriate use of acute headache medications by patients with frequent migraine or tension-type headache may contribute to the development of a chronic, daily (or almost daily) headache that is induced and maintained by the use of the painkilling drugs. This very aggressive and disabling type of headache, now labelled medication overuse headache $(\mathrm{MOH})$, is a largely under-diagnosed health condition, although it may affect $1-1.4 \%$ of the general population [1-6].

The clinical complexity of $\mathrm{MOH}$, formerly known by other names-such as drug-induced headache, painkiller headache, transformed migraine-or included in the group of chronic daily headache (CDH) [7], has probably contributed to difficulties in defining precise and widely accepted diagnostic criteria for the condition. Indeed, over the years different sets of diagnostic criteria have been proposed and the experts in the field have only recently reached a general consensus, which will probably favour the acquisition of the necessary information on this disabling disorder.

In this short paper, we discuss relevant epidemiological data available on $\mathrm{MOH}$, focusing on the information regarding this condition in Latin American (LA) countries, as a preparatory initiative to a project funded by the 
European Commission and aimed at improving collaboration and flow of information between Europe and Latin America (COMOESTAS Project-EC contract number 215366 (COMOESTAS) FP7-Thematic priority ICT, www.comoestas-project.eu).

\section{Methods: search strategy and selection criteria}

Data used for this review were extracted from the authors' files and completed with data obtained from scientific databases (i.e., PubMed or EMBASE) using the search terms "medication overuse headache", "drug-induced headache" or "chronic daily headache". Articles and citations were selected on the basis of their scientific validity, historical value, importance, relevance, and ease of access. All indexed papers in English, German and Spanish were included.

More than 140 articles in the above languages, published in the past three decades in indexed journals were identified. Of these, nearly 50 were included in the evaluation. Articles were excluded if they were not considered representative of the problem (single case reports, personal opinions of single researchers, MOH was not the main topic, etc.) or did not add important information or, again, had been already analysed in reviews included in this report.

\section{MOH: the history}

The clinical features of drug-induced headache were first described in 1951 in relation to excessively frequent or daily use of ergotamine [8]. Subsequently, the same authors described improvement after ergotamine withdrawal in 52 patients who had developed daily headache following daily intake of ergotamine [9]. As from 1970s, drug-induced headache was also described in patients using analgesics and other compounds [10]. There is now substantial evidence that all drugs used for the treatment of headache can cause $\mathrm{MOH}$ in patients with primary headache disorders [10]. The pattern of use of the drugs that can lead to $\mathrm{MOH}$ varies substantially from country to country and is influenced by cultural factors. In many patients, it is difficult to identify a single causal substance, since $90 \%$ of patients take more than one compound at a time and each of the single drug may, in theory, induce headache.

Many terms have been used to describe $\mathrm{MOH}$; in 1988 the condition was defined "drug-induced headache" by the International Headache Society [11]. This term, however, was criticized since several drugs, other than painkillers, can cause headache, even after a single dose, (nitrates, for example). In addition, it has been questioned whether headache can be primarily drug-induced [12]. Therefore, the headache associated with the use of symptomatic drugs was classified under the heading "Headache induced by chronic substance use or exposure"- - to distinguish it from the group of headaches induced by the acute use of drugsand included only two subtypes: headache induced by ergotamine and headache associated with analgesics. Studies conducted in the subsequent years, along with availability of new symptomatic drugs, suggested the need for a further revision of both the name and the diagnostic criteria [13-15]. In 2004, the term "medication overuse headache" was finally introduced into the second edition of the International Headache Society's Classification (International Classification of Headache Disorders-II edition, ICHD-II), also with the aim of emphasising excessive drug intake as the basis of this form of headache [16]. In ICHDII, MOH is classified amongst the secondary headache, within group 8: "Headache Attributed to a Substance or its Withdrawal". Together, the 2004 classification [16] and the two subsequent revisions of the diagnostic criteria for $\mathrm{MOH}[17,18]$ refine and extend the definition of this condition on the basis of both its chronicity (headache on more than 15 days/month for more than three months) and the different types of drugs overused, thereby identifying main types of $\mathrm{MOH}$. In the case of ergotamine, triptans, opioids and combination medications in particular, intake on $\geq 10$ days/month for $>3$ months is required, whereas simple analgesics are considered overused when they are taken on $\geq 15$ days/month for $>3$ months (Table 1 ).

\section{The epidemiological impact}

$\mathrm{MOH}$ is a largely under-diagnosed health condition, but its prevalence is increasing worldwide. Indeed, it is now the third most frequent type of headache [10, 19].

According to epidemiological surveys performed in the ' 80 s, between 1 and $3 \%$ of the general population take analgesics on a daily basis, and up to $7 \%$ take them at least once a week [20, 21]. Cross-sectional, population-based and epidemiological studies in Europe and Asia indicate that the prevalence of chronic headache associated with medication overuse is about $1-1.4 \%$ in the general population [1-6], with the prevalence peaking in women in their $50 \mathrm{~s}$. In this age range, indeed, $5 \%$ of women meet the diagnostic criteria for $\mathrm{MOH}[3,22]$. A meta-analysis of 29 studies involving 2,612 patients with chronic headache and analgesic overuse [23] confirmed the females predominance (F/M ratio: $3.5 / 1)$ and reported, in these patients, the simultaneous use of an average of between 2.5 and 5.8 (range 1-14) different pharmacological agents. The mean duration of primary headache at the time of diagnosis was 20.4 years, the mean duration of drug overuse was 
Table 1 Medication overuse headache: its subtypes and diagnostic criteria [16-18]
${ }^{a}$ Removed in latest revision [18]
8.2 Medication overuse headache (Previously used terms: rebound headache, drug-induced headache, medication-misuse headache)
Subtypes
8.2.1 Ergotamine overuse headache
8.2.2 Triptan-overuse headache
8.2.3 Analgesic overuse headache
8.2.4 Opioid overuse headache
8.2.5 Combination analgesic overuse headache
8.2.6 Medication overuse headache attributed to combination of acute medications
8.2.7 Headache attributed to other medication overuse
8.2.8 Probable medication overuse headache
Diagnostic criteria:
A Headache present on $>15$ days/month fulfilling criteria $\mathrm{C}$ and $\mathrm{D}^{\mathrm{a}}$
B Regular overuse for $>3$ months of 1 or more drugs that can be taken for acute and/or symptomatic treatment of headache.
C Headache has developed or markedly worsened during medication overuse.
D Headache resolves or reverts to its previous pattern within 2 months after discontinuation of overused medication $^{\mathrm{a}}$

10.3 years, and the mean duration of daily headache ( $>15$ days per month) was 5.9 years.

It is worth noting that the vast majority of these epidemiological studies investigated chronic headache following the overuse of analgesics or ergots diagnosed according to the International Headache Society's 1988 criteria [11] and, in part, the revised criteria of Silberstein et al. [15, 24]. Therefore, data from these studies must be interpreted cautiously, since they were conducted prior to the development of the ICHD-II criteria, and it is not possible to ascertain whether all the cases described really were $\mathrm{MOH}$ (improvement within 2 months of discontinuation of the overused medication now being required for a definite diagnosis of $\mathrm{MOH}$ ).

The situation will probably become clearer over the next years as a result of application of the International Headache Classification diagnostic criteria published in 2004 and alternative framing of data on the basis of the "new appendix criteria" for the diagnosis of $\mathrm{MOH}$, which, proposed for research purposes, no longer require the headache to improve after withdrawal [18].

Having outlined these premises, the currently available data on the impact of chronic headache associated with analgesic overuse in specialist headache centres confirm, beyond doubt, the existence of a serious health problem. In US specialist headache clinics, $60-80 \%$ of patients who presented with $\mathrm{CDH}$ used analgesics on a daily or neardaily basis [25-27]. More recently, a retrospective study conducted in a large, tertiary care headache centre in the United States (US) showed that the relative frequency of probable $\mathrm{MOH}$ in this setting had remained remarkably stable over the past 15 years [28], varying from $64 \%$ of all cases seen in the centre in 1990 to $59.3 \%$ in 2005 . At variance with these findings, in European headache centres, only $5-10 \%$ of patients presented with drug-induced headache [29-31]. MOH may also be a high-impact disease in general practice, as suggested by the results of a survey of 174 general practitioners in the US, which showed that chronic headache with overuse of symptomatic drugs is the third most common form of headache [32]. There is increasing evidence that the overuse of analgesics leading to $\mathrm{MOH}$ is a major epidemiological issue not only in Europe and North America, but also, more and more, in Asian countries, too; indeed, the prevalence of $\mathrm{MOH}$ in China and Taiwan is the same as that recorded in Europe $[1,2,5,21,33,34]$.

\section{MOH in Latin American countries}

Unfortunately, the epidemiological impact of $\mathrm{MOH}$ in LA countries is little known.

Indeed, some studies aiming at determining the prevalence of $\mathrm{CDH}$ have been conducted in Latin American [35, 36]. These studies point to a prevalence of $\mathrm{CDH}$ in Brazil that is higher than the prevalence recorded in countries outside of Latin America. However, it must be noted that these studies were about $\mathrm{CDH}$, but did not take into account the actual epidemiological impact of $\mathrm{MOH}$.

Indirect information can be derived by the study of Morillo et al. [37] where the authors describe the clinical characteristics and pattern of medication use of migraineurs in $12 \mathrm{LA}$ urban communities and report a total of $13 \%$ patients using symptomatic medication on at least 16 days per month.

Owing to this substantial lack of published data on the impact of MOH in LA countries, we planned a pilot study 
in collaboration with our LA partners (Argentina and Chile). The aim of this study was to estimate the impact of $\mathrm{MOH}$ in specialised headache centres. To this end, we developed a clinical report form for the diagnosis of $\mathrm{MOH}$ and the collection of relevant data from patients. This report form was administered to 100 consecutive patients referred to the Headache Centre of the Fleni Institute in Buenos Aires (Argentina) and to the Headache Centre of the Pontificia University of Santiago (Chile). According to the data supplied by our partners (Fadic R and Goicoichea MT, personal observations), in LA countries $\mathrm{MOH}$ accounts for between 55\% (the Chilean centre) and 70\% (the Argentinean centre) of headache patients seen in specialist centres. These findings, which will be better analysed by the COMOESTAS consortium, confirm the higher prevalence of $\mathrm{MOH}$ in subjects attending headache clinics; moreover, this result is similar to that found in tertiary headache clinics in US [28]. Of course, as in other studies, $\mathrm{MOH}$ patients who seek specialist care are likely to differ from $\mathrm{MOH}$ sufferers in the general population.

\section{MOH has changed over time}

The acute treatment of migraine has changed substantially over the past 15 years, following the marketing of the triptans, and so, too, has the type of $\mathrm{MOH}$. Four studies $[30,38-40]$ investigating the frequency of the headache associated with the use of various drugs were performed prior to the publication of the ICHD-2 diagnostic criteria for MOH. In a US study, combination analgesics containing butalbital (a short-acting barbiturate), caffeine, and aspirin with or without codeine emerged as the medications most likely to cause MOH [39]. Until the mid 1990s, combination analgesics with codeine or caffeine, or ergots combined with codeine were the most common headache therapies in many European countries [30, 38, 40].

However, the introduction of the triptans and the recent withdrawal of ergots from some markets (e.g., Germany) is changing this picture. In fact, since 1994, clinical reports have suggested that the triptan overuse, too, may lead to the development of MOH [41, 42]. Sumatriptan-induced MOH was first recorded in patients who had previously overused ergotamine [41, 43]. MOH was later reported [44] in patients using naratriptan, zolmitriptan, or rizatriptan. Typically, triptan-induced $\mathrm{MOH}$ appears 1 year after a drug has been commercialised [44]. Triptan-induced MOH shows more migrainous features, it develops more rapidly than that associated with other classes of symptomatic drugs, and is associated with a lower mean critical monthly dosage [45]. Increasing body of evidence suggests that all the available triptans can cause $\mathrm{MOH}[45,46]$ and reports on $\mathrm{MOH}$ induced by the newer triptans (eletriptan, frovatriptan, almotriptan) will probably appear in the next future.

A study based on the prescription register in Denmark revealed that the prevalence of sumatriptan use in the Danish population, in 1995 , was $0.78 \%$. Of these users, up to $5 \%$ overused sumatriptan on a daily basis [47]. Evers and colleagues found that $4.7 \%$ of 320 sumatriptan users overused the drug by taking it at least every other day [48]. A recent population-based study in France revealed that triptans are used in a low percentage $(7.5 \%)$ of migraine patients, but in a definitely higher proportion $(25 \%)$ of patients with CDH [49]. This latter observation suggest a potential causal relationship between triptan misuse and development of daily chronic headache, although future studies are needed to address this issue.

\section{MOH in children and adolescents}

Several studies have addressed the prevalence of chronic headache in early adolescence and even in childhood [50, 51]. Hering-Hanit and Gadoth [51] reported daily or neardaily headache related to excessive consumption of caffeine in a group of 36 children and adolescents aged from 6 to 18 years; in this study, the mean age of the subjects was 9.2 years, with a mean duration of headache of 1.8 years; thus, indicating that overuse may also begin very early. Adolescents with analgesic-induced headache responding to withdrawal treatment have also been reported [52]; however, conclusive data are missing on the real dimension of the problem. The scarce data available from the literature seem to suggest that $\mathrm{MOH}$ in children and adolescents may be less frequent than in adults. In one populationbased study conducted in Taiwan, the authors reported a prevalence of $1.5 \%$ of $\mathrm{CDH}$ in a population of adolescents (12-14 years of age) and MOH was present only in $1 / 5$ of these subjects [53]. Furthermore, a study from Canada, conducted in a general paediatric neurology ambulatory practice, showed that daily chronic headache prevalence was $3 \%$ in a group of 1,669 children seen because of headache. In this small subset of children suffering from chronic headache, medication overuse was present in 50\% of cases [54].

\section{Conclusion}

The data illustrated confirm that $\mathrm{MOH}$ is a chronic disorder and major health problem that affects a huge number of subjects, including youngsters. Although scientific data is limited, $\mathrm{MOH}$, on account of its clinical characteristics, is clearly a cause of disability and, if not adequately treated, of co-morbidity due to the excessive intake of drugs. 
$\mathrm{MOH}$ can be treated through withdrawal of the overused $\operatorname{drug}(\mathrm{s})$ and adopting specific approaches that focus on the development of a close doctor-patient relationship in the post-withdrawal period.

\section{Conflict of interest None}

\section{References}

1. Castillo J, Muñoz P, Guitera V et al (1999) Epidemiology of chronic daily headache in the general population. Headache 39:190-196

2. Lantéri-Minet M, Auray JP, El Hasnaoui A et al (2003) Prevalence and description of chronic daily headache in the general population in France. Pain 102:143-149

3. Colás R, Muñoz P, Temprano R et al (2004) Chronic daily headache with analgesic overuse: epidemiology and impact on quality of life. Neurology 62:1540-1544

4. Scher AI, Stewart WF, Liberman J et al (1998) Prevalence of frequent headache in a population sample. Headache 38:497-506

5. Lu SR, Fuh JL, Chen WT, Juang KD, Wang SJ (2001) Chronic daily headache in Taipei, Taiwan: prevalence, follow up and outcome predictors. Cephalalgia 21:980-986

6. Zwart JA, Dyb G, Hagen K, Svebak S, Holmen J (2003) Analgesic use: a predictor of chronic pain and medication overuse headache: the Head-HUNT Study. Neurology 61:160-164

7. Sjaastad O (1985) "Chronic daily headache" ("cefalea cronica quotidiana"). Cephalalgia 5(Suppl 2):191-193

8. Peters GA, Horton BT (1951) Headache: with special reference to the excessive use of ergotamine preparations and withdrawal effects. Mayo Clin Proc 26:153-161

9. Horton BT, Peters GA (1963) Clinical manifestations of excessive use of ergotamine preparations and management of withdrawal effect: report of 52 cases. Headache 3:214-226

10. Diener H-C, Limmroth V (2004) Medication-overuse headache: a worldwide problem. Lancet Neurol 3:475-483

11. Headache Classification Committee of the International Headache Society (1988) Classification and diagnostic criteria for headache disorders, cranial neuralgias and facial pain. Cephalalgia 8:1-93

12. Konno S, Meyer J, Margishvili G, Rauch R, Haque A (1999) Transformed migraine is a cause of chronic daily headaches. Headache 39:95-100

13. Diener HC, Dahlof CG (1999) Headache associated with chronic use of substances. In: Olesen J, Tfelt Hansen P, Welch KM (eds) The headaches, 2nd edn. Lippincott, Williams \& Wilkins, Philadelphia, pp 871-878

14. Diener HC (1993) A personal view of the classification and definition of drug dependence headache. Cephalalgia 13(Suppl 12):68-71

15. Silberstein SD, Lipton RB, Sliwinski M (1996) Classification of daily and near-daily headaches: field trial of revised IHS criteria. Neurology 47:871-875

16. International Headache Society (2004) The international classification of headache disorders: 2nd edition. Cephalalgia 24(Suppl 1): $9-160$

17. Silberstein S, Olesen J, Bousser MG et al (2005) The international classification of headache disorders 2 nd ed. (ICHD-II). Revision of criteria for 8.2 medication-overuse headache. Cephalalgia 25:460-465

18. Olesen J, Bousser MG, Diener HC et al (2006) New appendix criteria open for a broader concept of chronic migraine. Cephalalgia $26: 742-746$
19. Limmroth V, Katsarava Z (2004) Medication overuse headache. Curr Opin Neurol 17:301-306

20. Schwarz A, Farber U, Glaeske GM (1985) Daten zu Analgetikakonsum und Analgetikanephropathie in der Bundesrepublik. Öffentliches Gesundheitswesen 47:298

21. Gutzwiller F, Zemp E (1986) Der Analgetikakonsum in der Bevölkerung und socioökonomische Aspekte des Analgetikaabusus. In: Mihatsch MJ (ed) Das Analgetikasyndrom. Stuttgart, Thieme, p 197

22. Zwart JA, Dyb G, Hagen K, Svebak S, Stovner LJ, Holmen J (2004) Analgesic overuse among subjects with headache, neck, and low-back pain. Neurology 62:1540-1544

23. Diener HC, Tfelt-Hansen P (1993) Headaches associated with chronic use of substances. In: Olesen J, Tfelt-Hansen P, Welch KMA (eds) The headaches. Raven Press, New York, pp 721-727

24. Silberstein SD, Lipton RB, Solomon S, Mathew NT (1994) Classification of daily and near-daily headaches: proposed revisions to the IHS criteria. Headache 34:1-7

25. Mathew N, Stubits E, Nigam MR (1982) Transformation of episodic migraine into daily headache: analysis of factors. Headache 22:66-68

26. Mathew N, Reuveni U, Pérez F (1987) Transformed or evolutive migraine. Headache 27:102-106

27. Saper JR, Dodick D, Gladstone JP (2005) Management of chronic daily headache: challenges in clinical practice. Headache 45(Suppl 1):S74-S85

28. Meskunas CA, Tepper SJ, Rapoport AM, Sheftell FD, Bigal ME (2006) Medications associated with probable medication overuse headache reported in a tertiary care headache center over a 15 year period. Headache 46:766-772

29. Granella F, Farina S, Malferrari G, Manzoni GC (1987) Drug abuse in chronic headache: a clinical-epidemiologic study. Cephalalgia 7:15-19

30. Micieli G, Manzoni GC, Granella F (1988) Clinical and epidemiological observations on drug abuse in headache patients. In: Diener HC, Wilkinson $\mathrm{M}$ et al (eds) Drug-induced headache. Springer, New York, pp 20-28

31. Pascual J, Berciano J (1993) Cefalea crónica diaria de pacientes migrañosos inducida por abuso de analgésicos-ergotamínicos: respuesta a un protocolo de tratamiento ambulatorio. Neurologia $8: 212-215$

32. Rapoport A, Stang P, Gutterman DL et al (1996) Analgesic rebound headache in clinical practice: data from a physician survey. Headache 36:14-19

33. Prencipe M, Casini AR, Ferretti C et al (2001) Prevalence of headache in an elderly population: attack frequency, disability, and use of medication. J Neurol Neurosurg Psychiatry 70:377381

34. Wang SJ, Fuh JL, Lu SR et al (2000) Chronic daily headache in Chinese elderly: prevalence, risk factors, and biannual follow-up. Neurology 54:314-319

35. Queiroz LP, Barea LM, Blank N (2005) An epidemiological study of headache in Florianopolis, Brazil. Cephalalgia 26:122127

36. Queiroz LP, Peres MF, Kowacs F et al (2008) Chronic daily headache in Brazil: a nationwide population-study. Cephalalgia 28:1264-1269

37. Morillo LE, Alarcon F, Aranaga N et al (2005) Clinical characteristics and patterns of medication use of migraneurs in Latin America from 12 cities in 6 countries. Headache 45:118-126

38. Baumgartner C, Wessely P, Bingöl C, Maly J, Holzner F (1989) Longterm prognosis of analgesic withdrawal in patients with drug-induced headaches. Headache 29:510-514

39. Mathew NT, Kurman R, Perez F (1990) Drug induced refractory headache: clinical features and management. Headache 30:634638 
40. Diener HC, Bühler K, Dichgans J et al (1988) Analgetikainduzierter Dauerkopfschmerz. Existiert eine kritische Dosis? Arzneimitteltherapie 6:156-164

41. Kaube H, May A, Diener HC, Pfaffenrath V (1994) Sumatriptan misuse in daily chronic headache. Br Med J 308:1573-1574

42. Pini LA, Trenti T (1994) Case report: does chronic use of sumatriptan induce dependence? Headache 34:600-601

43. Catarci T, Fiacco F, Argentino C, Sette G, Cerbo R (1994) Ergotamine-induced headache can be sustained by sumatriptan daily intake. Cephalalgia 14:374-375

44. Limmroth V, Katsarava Z, Fritsche G, Diener H-C (1999) Headache after frequent use of new 5-HT agonists zolmitriptan and naratriptan. Lancet 353:378

45. Limmroth V, Katsarava Z, Fritsche G, Przywara S, Diener H-C (2002) Features of medication overuse headache following overuse of different acute headache drugs. Neurology 59:1011-1014

46. Bigal ME, Rapoport AM, Sheftell FD, Tepper SJ, Lipton RB (2004) Transformed migraine and medication overuse in a tertiary headache centre-clinical characteristics and treatment outcomes. Cephalalgia 24:483-490

47. Gaist D, Hallas J, Sindrup SH, Gram LF (1996) Is overuse of sumatriptan a problem? A population-based study. Eur J Clin Pharmacol 3:161-165
48. Evers S, Bauer B, Suhr B, Wieser T, Husstedt I (1997) The epidemiology of sumatriptan abuse. In: Olesen J, Tfelt-Hansen P (eds) Headache treatment: trial methodology and new drugs (Frontiers in headache research, vol 6). Lippincott, Williams \& Wilkins, Philadelphia, pp 149-52

49. Lucas C, Auray JP, Gaudin AF et al (2004) Use and misuse of triptans in France: data from the GRIM2000 population survey. Cephalalgia 24:197-205

50. Hershey AD (2003) Chronic daily headaches in children. Expert Opin Pharmacother 4:485-491

51. Hering-Hanit R, Gadoth N (2003) Caffeine-induced headache in children and adolescents. Cephalalgia 23:332-335

52. Symon DN (1998) Twelve cases of analgesic headache. Arch Dis Child 78:555-556

53. Wang SJ, Fuh JL, Lu SR, Juang KD (2006) Chronic daily headache in adolescents. Prevalence, impact, and medication overuse. Neurology 66:193-197

54. Moore AJ, Shevell M (2004) Chronic daily headaches in pediatric neurology practice. J Child Neurol 19:925-929 